\title{
Venous Thromboembolism Prophylaxis: A Survey among the Medical Staff of Intensive Care Unit and Surgery Ward in Tertiary Care Teaching Hospital
}

\author{
Vinod Kumar $^{1, *}$, Shraddha P Devarshi ${ }^{2}$ \\ ${ }^{1}$ Department of Clinical Pharmacy, Bharati Vidyapeeth (Deemed University), Pune, Maharashtra, INDIA. \\ ${ }^{2}$ Department of Pharmacy Practice, Indira College of Pharmacy, Pune, Maharashtra, INDIA.
}

\begin{abstract}
Background: Venous Thromboembolism (VTE) prophylaxis is underutilized in India. This study was designed to evaluate knowledge, attitude and practices of healthcare providers towards VTE prophylaxis in a teaching hospital in Pune. Methods: Knowledge, attitude and practices was assessed by a 10 -item questionnaire filled by healthcare providers in intensive care unit and surgery ward of tertiary care teaching hospital. Nine out of 10 questions were multiple-choice type and one was open ended. Results: Out of 60 questionnaires distributed, 40 were completed and returned. Out of 40, $22(55 \%)$ were from ICU/HDU (Intensive Care Unit/High Dependency Unit) and 18 $(45 \%)$ were from surgery. Although most of the $40(100 \%)$ of the respondent agreed that VTE prophylaxis was clinically important but only $85 \%(34 / 40)$ had actually prescribed it themselves. Among the responder in ICU/ HDU it was found that routine prophylaxis was claimed by $18(81 \%)$ of respondent while in prolonged surgery and post-operative it was $12(54.54 \%) .36 .36 \%$ of non-prescriber in ICU and $22.22 \%$ in surgery thought that DVT prophylaxis is not relevant to their setup or have very low risk of DVT. In ICU as per respondents $27.27 \%$ patients may develop VTE after discharge and around $45.45 \%$ are unable to answer the question. In surgery as per respondents $11.11 \%$ patients may develop VTE after discharge and around $77.77 \%$ are unable to answer the question. Conclusion: Knowledge and practices of healthcare providers about VTE prophylaxis in hospitalized patients is less than ideal. Hospitals need to arrange sensitization lectures for the awareness of VTE Scoring, prophylaxis in ICU/HDU, Surgery and to develop their own guidelines for VTE prophylaxis.
\end{abstract}

Key words: Knowledge, Attitude, Practices, DVT Prophylaxis, Intensive Care Unit, Surgery.

\section{INTRODUCTION}

Venous Thromboembolism (VTE) is a common medical condition that manifests as Deep Vein Thrombosis (DVT) and Pulmonary Embolism (PE). Critically ill patients in the Intensive Care Unit (ICU) are at high risk for VTE because of their specific conditions, such as immobilization, post-operative status, sepsis, mechanical ventilation, central venous catheter use. It depends upon a number of predisposing factors like increasing age, type of surgery, previous history of Deep Vein Thrombosis (DVT) and immobility. ${ }^{1}$ Without any prophylaxis, the risk of developing DVT in hospitalized patients is $10-40 \%$ while for patients having orthopedic surgery it is much higher, about $60-80 \%{ }^{2,3}$ Almost $10 \%$ of all hospital deaths can be attributed to
Pulmonary Embolism (PE). ${ }^{4}$ Moreover about one-third of patients with DVT develop chronic complications including post thrombotic limb syndrome, chronic embolic pulmonary hypertension and a higher risk of recurrent DVT. ${ }^{5}$ There is certain clinical evidence that thromboprophylaxis reduces the risk of DVT and PE. ${ }^{1,6,7}$ Although numerous guidelines on use of thromboprophylaxis are available for many years, yet thromboprophylaxis remains underused throughout the world. ${ }^{1,3,8-11}$ No published data exists about the reasons for underutilization of DVT prophylaxis, awareness of health care professionals and availability of standard DVT prophylaxis guidelines in hospitals of India. We have designed this study to gauge knowledge of
DOI: 10.5530/ijopp.12.4.50

Address for

correspondence:

Dr. Vinod Kumar,

Department of Clinical Pharmacy,

Bharati Vidyapeeth Deemed

University, Pune-411038, Maharashtra, INDIA.

Phone no: +91 6353387675

Email Id: vinod.shukla1991@ gmail.com

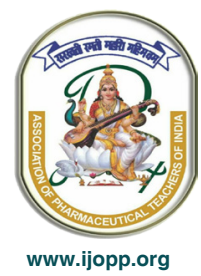


healthcare professionals regarding prevalence of DVT, their attitude towards its importance and their practices towards its implementation. Based on the results of this study we can direct efforts to improve compliance with standard recommendations for DVT prophylaxis.

\section{MATERIALS AND METHODS}

A questionnaire was created by clinical pharmacist in consultation with specialists who are experts in the fields of VTE and critical care medicine. A questionnaire was designed to assess Knowledge Attitude and Practices (KAP) of healthcare providers towards DVT prophylaxis. Questionnaire was kept simple and short so that it could be filled quickly and easily. To assess clarity and consistency of questions, an initial pilot run was carried out. After analyzing the results of pilot 10 questions were finalized. Nine out of 10 questions were multiple-choice type and one was open ended.

This questionnaire was distributed to a cross section of practicing consultant general surgeons in the ICU/ HDU and surgery ward of Bharati Hospital and Research Center, Pune during ward rounds. ICU/HDU included surgical, medical and other specialized ICUs. Participants included the physicians, senior resident and junior resident working in these ICU and Surgery. The questionnaires to healthcare providers were personally delivered with a request to complete them to the best of their knowledge without consulting colleagues. Respondents were required to mention their name, specialty and grade. The survey questionnaire covering 4 dimensions: (1) general information on the participant, (2) clinical importance and awareness of relevant guidelines that address VTE prophylaxis in respective wards (3) the practice pattern of VTE prophylaxis and (4) concerns regarding VTE prophylaxis.

This study was carried out from July to August 2017. A total of 60 questionnaires were distributed, collected and analyzed using descriptive statistics.

\section{RESULTS}

Out of 60 questionnaires distributed, 40 were completed and returned. Out of 40, 22 (55\%) were from ICU/HDU and $18(45 \%)$ were from surgery. Results were analyzed using SPSS-15. Table 1 show grades of healthcare professionals who responded to the questionnaire.

Responses to each question are listed in Table 2. Although most of the $40(100 \%)$ of the respondent agreed that DVT prophylaxis was clinically important only $85 \%$ $(34 / 40)$ had actually prescribed it themselves. Among the responder in ICU/HDU it was found that routine
Table 1: Grades of respondents from ICU/HDU and Surgery.

Grade

Percentage (\%) Respondent (n)

\begin{tabular}{ccc}
\hline Consultant & 10 & 4 \\
Assistant Professor & 15 & 6 \\
Senior Resident & 32.5 & 13 \\
Junior Resident & 42.5 & 17 \\
\hline
\end{tabular}

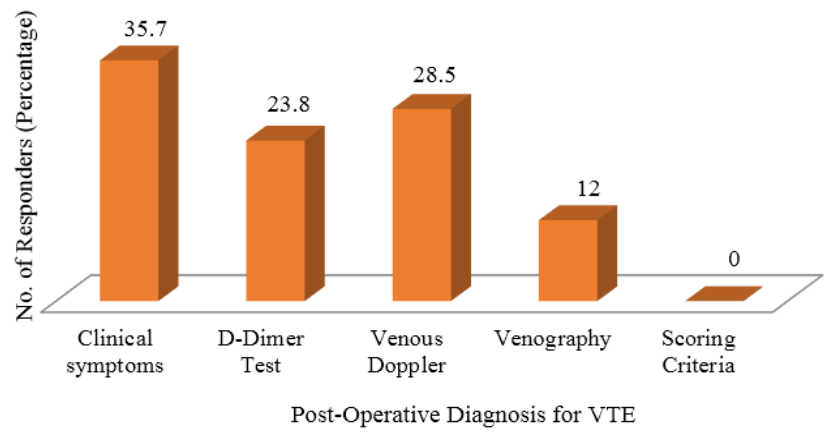

Figure 1: Post-operative diagnosis of VTE (Percentage).

prophylaxis was claimed by $18(81 \%)$ of respondent while in prolonged surgery and post-operative it was 12 (54.54\%). Non prescriber $8(36.36 \%)$ in ICU thought that DVT prophylaxis is not relevant to the setup.

In ICU, almost $2(9.09 \%)$ thought that risk outweighs benefit and in surgery $6(33.33 \%)$ had been told by seniors not to prescribe it. Almost $1 / 4^{\text {th }}(25.92 \%)$ of medical/ surgical units have no set policy for DVT prophylaxis as per respondents. According to the respondent, $20(50 \%)$ said incidence of DVT is same as western, 18 (45\%) said less than western and $2(5 \%)$ didn't answer. In ICU $16(72.72 \%)$ and in surgery $12(66.66 \%)$ respondents do not score routinely patients on their VTE risk. In ICU $6(27.27 \%)$ respondents thought patients may develop VTE after discharge and around $10(45.45 \%)$ are unable to answer the question. In surgery $2(11.11 \%)$ respondents said patients may develop VTE after discharge and around $14(77.77 \%)$ are unable to answer the question. Figure 1 show percentages of respondents using different methods for post-operative diagnosis of VTE.

\section{DISCUSSION}

VTE is a major cause of morbidity and mortality in hospitalized patients. The risk of VTE can be decreased by using guidelines and interventions. ${ }^{12,13}$ The incidence of VTE has traditionally been considered to be lower in Asian populations as compared to western ones. However recent studies have challenged this perception with increasing incidence of VTE being reported. One reason for this being that earlier Asian studies tended to report only those VTE events that were symptomatic and 
Table 2: Responses of respondents from various Departments.

\begin{tabular}{|c|c|c|c|c|}
\hline Questions & Responses & ICU / HDU & Surgery & Total n (\%) \\
\hline \multirow{3}{*}{$\begin{array}{l}\text { Do you think VTE prophylaxis is clinically } \\
\text { important }\end{array}$} & Yes & 22 & 18 & $40 / 40(100 \%)$ \\
\hline & No & 0 & 0 & 0 \\
\hline & Yes & 18 & 8 & $26 / 40(65 \%)$ \\
\hline \multirow{2}{*}{$\begin{array}{l}\text { Does our hospital/unit have a policy regarding } \\
\text { VTE prophylaxis? }\end{array}$} & No & 4 & 2 & $6 / 40(15 \%)$ \\
\hline & Do not know & 0 & 8 & $8 / 40(20 \%)$ \\
\hline \multirow{2}{*}{$\begin{array}{l}\text { Do you prescribe thromboprophylaxis for VTE risk } \\
\text { patient? }\end{array}$} & Yes & 20 & 14 & $34 / 40(85 \%)$ \\
\hline & No & 2 & 4 & $6 / 40(15 \%)$ \\
\hline \multirow{5}{*}{$\begin{array}{l}\text { If you do not prescribe VTE prophylaxis routinely, } \\
\text { why is that? }\end{array}$} & Do not feel important & 0 & 2 & $2 / 40(5 \%)$ \\
\hline & Risk outweigh benefit & 2 & 0 & $2 / 40(5 \%)$ \\
\hline & Cost & 4 & 4 & $8 / 40(20 \%)$ \\
\hline & Not relevant to our setup & 8 & 0 & $8 / 40(20 \%)$ \\
\hline & $\begin{array}{l}\text { Told by seniors not to } \\
\text { prescribe }\end{array}$ & 0 & 6 & $6 / 40(15 \%)$ \\
\hline \multirow{4}{*}{$\begin{array}{l}\text { Have you encountered case of post-operative VTE } \\
\text { in our hospital }\end{array}$} & Other & 8 & 6 & $14 / 40(35 \%)$ \\
\hline & Yes & 15 & 12 & $27 / 40(67.5)$ \\
\hline & No & 7 & 4 & $11 / 40(27.5)$ \\
\hline & Do not know & 0 & 2 & $2 / 40(5 \%)$ \\
\hline \multirow{5}{*}{$\begin{array}{l}\text { How do you diagnose postoperative VTE in our } \\
\text { hospital }\end{array}$} & Clinical symptoms & 20 & 10 & $30 / 84(35.7 \%)$ \\
\hline & Scoring Criteria & 0 & 0 & 0 \\
\hline & D-Dimer Test & 16 & 4 & $20 / 84(23.8 \%)$ \\
\hline & Venous Doppler & 10 & 14 & $24 / 84(28.5 \%)$ \\
\hline & Venography & 2 & 8 & $10 / 84(12 \%)$ \\
\hline \multirow{3}{*}{ In your experience how prone are Indian to VTE } & Same as Western & 10 & 10 & $20 / 40(50 \%)$ \\
\hline & Less than western & 12 & 6 & $18 / 40(45 \%)$ \\
\hline & Not answerable & 0 & 2 & $2 / 40(5 \%)$ \\
\hline \multirow{3}{*}{$\begin{array}{c}\text { A significant no. of patients develop VTE after } \\
\text { discharge }\end{array}$} & True & 6 & 2 & $8 / 40(20 \%)$ \\
\hline & False & 6 & 2 & $8 / 40(20 \%)$ \\
\hline & Not answerable & 10 & 14 & $24 / 40(60 \%)$ \\
\hline \multirow{2}{*}{$\begin{array}{l}\text { Do your routinely score patients pre-operatively on } \\
\text { their VTE risk? }\end{array}$} & Yes & 6 & 6 & $12 / 40(30 \%)$ \\
\hline & No & 16 & 12 & $28 / 40(70 \%)$ \\
\hline \multirow{2}{*}{$\begin{array}{l}\text { Do you believe that a standard thrombo- } \\
\text { prophylaxis guidline should be implemented for } \\
\text { our hospital? }\end{array}$} & Yes & 22 & 16 & $38 / 40(95 \%)$ \\
\hline & No & 0 & 2 & $2 / 40(5 \%)$ \\
\hline
\end{tabular}

specific patient populations like postoperative orthopedic patients. Whereas western studies documented both symptomatic as well as asymptomatic events on the basis of bilateral venography, leading to the impression of lower risk among Asian populations. Leizorovicz et al. were the first to suggest that VTE was a significant problem in Asians. ${ }^{14}$ The incidence of VTE in India is highly underestimated because of lack of adequate studies highlighting the incidence of VTE especially in medical patients. There are few but conflicting studies in post-surgical patients and paucity of data from autopsied patients as autopsy is being done in very few institutions in India. ${ }^{15-18}$

This paved the way for numerous other prospective studies in Asian countries which reported rising rates of VTE and PE with incidences around 17-20/1000. ${ }^{15,19} \mathrm{In}$ our survey, $50 \%$ of the respondents in our survey believed that Indians were at the same risk for VTE as western populations. Indian studies on the subject are largely inadequate and conflicting, with older studies showing lower rates of VTE incidence ${ }^{20,21}$ and newer ones higher. A recent study conducted at $\mathrm{CMC}$ Vellore reported an incidence of $17.46 / 10000$ hospital admissions which is comparable to other Asian results. ${ }^{22}$ This suggests that the perceived lower incidence in Indians might in fact be due to a lack of awareness and inadequate diagnostic facilities. An autopsy study performed on 1000 patients at Post Graduate Institute Chandigarh in North India found fatal pulmonary embolism in $16 \%$ of cases. ${ }^{23}$ 
The findings of our survey suggest that use of routine thromboprophylaxis is less for all cases so it should be considered for Indians which are at high risk.

The overall knowledge on VTE prophylaxis among our respondents was far below the ideal. It may be related to the fact that the condition is not often diagnosed, added to the low practice of autopsy to determine the gravity of the disease.

$23.8 \%$ respondents said that they used $\mathrm{D}$-dimer assay. The ACCP recommends that the diagnostic test is dependent on the pretest probability of VTE. In low-to-moderate VTE risk, D-dimer is advocated as the diagnostic test of choice. In high VTE risk whole-leg ultrasound is preferred. ${ }^{24} 70 \%$ of respondents said that they do not score patients preoperatively for VTE.

95\% of these surgeons believed that an institute-based protocol should be in place. The ACCP advocates that each institute adopt its own protocol for VTE prophylaxis. ${ }^{25}$ Despite the establishment of guidelines and protocols, numerous studies have shown that adequate prophylaxis is not being offered to a large number of surgical patients across the world. The most significant of these is the ENDORSE study which included 30827 patients from 32 countries including India. Out of 19842 surgical patients at risk for VTE, $41.5 \%$ of cases did not receive proper prophylaxis. ${ }^{11}$ In the Indian patients enrolled in the ENDORSE study, only $16.3 \%$ of at-risk surgical patients received adequate prophylaxis. ${ }^{26}$

$8(20 \%)$ of the respondents in our study said they believed thromboprophylaxis would add to the burden of cost and $8(20 \%)$ respondent said that thromboprophylaxis is not relevant to their setup.

These findings suggest that efforts need to be taken to improve the awareness among surgeons regarding how to score patients for their VTE risk and regarding the appropriate prophylaxis methods to be used for each risk group.

Several Asian countries including Japan and Korea have adopted their own national guidelines for VTE prophylaxis. ${ }^{27,28}$ These follow the ACCP guidelines for prophylaxis but differ in the fact that they score their populations at one level higher than those recommended by the ACCP. In view of the evidence documenting the risk for VTE in Indians, evolution of Indian guidelines for VTE prophylaxis appears to be in order. Many surgeons believe that the same scoring criteria used for western populations would not be appropriate for Indian patients and are hence reluctant to use ACCP guidelines. Adoption of our own national guidelines would increase awareness for VTE and ensure uniformity in prophylaxis protocols used.

Our survey was limited by the fact that it was conducted in single hospital in India. At present we are in the process of doing drug utilization of thromboprophylaxis. Moving forward, we believe there is a need to increase awareness among general surgeons regarding the need for VTE prophylaxis and the adoption of institute-based protocols for the same. At a national level, epidemiological studies should be undertaken to ascertain the risk of Indian populations for VTE and national guidelines for prophylaxis need to be established.

\section{CONCLUSION}

Our survey was aimed at analyzing the knowledge, attitude and practices of Indian surgeons for VTE prophylaxis. We found that almost all surgeons had encountered VTE and very less had seen mortality from the same. We found that most surgeons do not score patients preoperatively for their risk and hospital do not have institute-based protocols. We also found inadequate knowledge among surgeons regarding prophylaxis methods and a lack of uniformity in the currently used methods. We would advocate for greater awareness and education of surgeons on this topic and encourage them to adopt best practice guidelines for VTE prophylaxis. Hospitals and units should be urged to formulate their own guidelines for managing VTE.

\section{ACKNOWLEDGEMENT}

The author are thankful to Department of Surgery and ICU for their co-operation and guidance.

\section{CONFLICT OF INTEREST}

The authors declare that there are no conflicts of interest.

\section{ABBREVIATIONS}

VTE: Venous Thromboembolism; ICU: Intensive Care Unit; ACCP: American College of Chest Physicians; CMC: Christian Medical College; ENDROSE: Epidemiologic International Day for the Evaluation of Patients at Risk for Venous Thromboembolism in the Acute Hospital Care Setting; DVT: Deep Venous Thrombosis; PE: Pulmonary Embolism; HDU: High Dependency Unit.

\section{SUMMARY}

The research summaries that there is a need to formulate VTE prophylaxis guidelines so the risks and complications can be timely managed. 


\section{REFERENCES}

1. Dhanesh R, Kamerkar M, Joseph J, Sanjay CD, Dsilva LC, Joglekar SJ. Arrive: A retrospective registry of Indian patients with venous thromboembolism. Indian Journal of Critical Care Medicine. 2016;20(3):150-8. doi: 10.4103/09725229.178178 .

2. Sayyed EHN, Mohammed AH, Mohammed HB. Deep vein thrombosis: An experience of 25 years from north India. Indian Journal of Vascular and Endovascular Surgery. 2016;3(1):2-6. doi: 10.4103/0972-0820.180199

3. Clagett GP, JrAnderson FA, Greets W, Heit JA, Knudson M, Lieberman JR, et al. Prevention of venous thromboembolism. Chest. 1998;114(5):531-60. DOI: 10.1378/chest.114.5_supplement.531s.

4. Sandler DA, Martin JF. Autopsy proven pulmonary embolism in hospitalised patients: Are we detecting enough deep vein thrombosis?. J R Soc Med. 1989;82(4):203-5. DOI:10.1177/014107688908200407

5. Prandoni P, Villalta S, Bagatella P, Ross Li, Marchiori A, Piccioli A, et al. The clinical course of deep-vein thrombosis. Prospective long-term follow-up of 528 symptomatic patients. Haematologica. 1997;82(4):423-8.

6. Prevention of fatal pulmonary embolism by low doses of heparin. An international multicentre trial. The Lancet. 1975;2:(306):45-51.

7. Group Second Thromboembolic Risk Factors (THRiFT II) Consensus group. Risk of and prophylaxis for venous thromboembolism in hospital patients. Phlebology. 1998;13(3):87-97. doi: 10.1136/bmj.305.6853.567

8. Yu HT, Dylan ML, Lin J, Dubois RW. Hospital's compliance with prophylaxis guidelines for venous thromboembolism. Am J Health Sys Pharm. 2007;64(1):69-76. DOI: 10.2146/ajhp060115

9. Ansari K, Dalal K, Patel M. Risk stratification and utilization of thromboembolism prophylaxis in a medical-surgical ICU: Hospital-based study. J Indian Med Assoc. 2007;105(9):536-40.

10. Ambarish P, Nivedita P, Mansher S. Assessment of risk and prophylaxis for deep vein thrombosis and pulmonary embolism in medically ill patients during their early days of hospital stay at a tertiary care center in a developing country. Vasc Health Risk Manag. 2009;5:643-8.

11. Cohen AT, Tapson VF, Bergmann JF, Goldhaber SZ, Kakkar AK, Deslandes B, et al. Venous Thromboembolism risk and prophylaxis in acute hospital care setting (ENDORSE study): A multinational cross-sectional study. Lancet. 2008;371(9610):387-9. DOI: 10.1016/S0140-6736(08)60202-0

12. Heit JA, Silverstein MD, Mohr DN, Petterson TM, O'Fallon WM, Melton LJ. Risk factors for deep vein thrombosis and pulmonary embolism: A population-based case control study. Arch Intern Med. 2000;160(6):809-15.

13. Alikhan R, Cohen AT, Combe S, Samama MM, Desjardins L, Eldor A, et al. Risk factors for venous thromboembolism in hospitalized patients with acute medical illness: Analysis of the MEDENOX Study. Arch Intern Med. 2004;164(9):963-8. [DOI: 10.1001/archinte.164.9.963]

14. Leizorovicz A, Turpie AGG, Cohen AT, Dhillon KS, Angchaisuksiri P, Wang CJ. Epidemiology of postoperative venous thromboembolism in Asian countries. International Journal of Angiology. 2004;13(3):101-8.
15. Lee LH, Gu KQ, Heng D. Deep vein thrombosis is not rare in Asia--the Singapore General Hospital experience. Ann Acad Med Singapore. 2002;31(6):761-4.

16. Dhillon KS, Askander A, Doraismay S. Postoperative deep-vein thrombosis in Asian patients is not a rarity: A prospective study of 88 patients with no prophylaxis. J Bone Joint Surg Br. 1996;78(3):427-30.

17. Ko PS, Chan WF, Siu TH, Khoo J, Wu WC, Lam JJ. Deep venous thrombosis after total hip or knee arthroplasty in a "low-risk" Chinese population. J Arthroplasty. 2003;18(2):174-9.

18. Gandharba R, Manoranjan B. Venous thromboembolism- Indian perspective. Medical Update. 2010;20:229-334.

19. Piovella F, Wang CJ, Lu H, Lee K, Lee LH, Lee WC, et al. Deep-vein thrombosis rates after major orthopedic surgery in Asia. An epidemiological study based on postoperative screening with centrally adjudicated bilateral venography. Journal of Thrombosis and Haemostasis. 2005;3(12):2664-70. [ DOI: 10.1111/j.15387836.2005.01621.x]

20. Jain V, Dhaon DK, Jaiswal A, Nigam V, Singla J. Deep vein thrombosis after total hip and knee arthroplasty in Indian patients. Postgraduate Medical Journal. 2004;80(950):729-31.

21. Bagaria V, Modi N, Panghate A, Vaidya S. Incidence and risk factors for development of venous thromboembolism in Indian patients undergoing major orthopaedic surgery: Results of a prospective study. Postgraduate Medical Journal. 2006;82(964):136-9. doi: 10.1136/pgmj.2005.034512

22. Lee AD, Stephen E, Agarwal S, Premkumar P. Venous Thrombo-embolismin India. European Journal of Vascular and Endovascular Surgery. 2009;37(4):4825.

23. Kakkar N, Vasishta RK. Pulmonary embolism in medical patients: An autopsybased study. Clinical and Applied Thrombosis/ Hemostasis. 2008;14(2):159-67.

24. Bates SM, Jaeschke R, Stevens SM, Goodacre S, Wells PS, Matthew D, et al. Diagnosis of DVT: Antithrombotic therapy and prevention of thrombosis, $9^{\text {th }}$ ed. American College of Chest Physicians evidence-based clinical practice guidelines. Chest. 2012;141(2):351-418. DOI: https://doi.org/10.1378/ chest.11-2299.

25. Gould MK, David A, Wren SM, Karanicolas PJ, Arcelus JI, Heit JA, et al. Prevention of VTE in nonorthopedic surgical patients: Antithrombotic therapy and prevention of thrombosis, $9^{\text {th }}$ ed, American College of Chest Physicians Evidence-Based Clinical Practice Guidelines. Chest. 2012;141(2 suppl):e227S77S. DOI: 10.1378/chest.11-2297.

26. Pinjala R, Agnihotri V, Balraj A, Amiya C, Sanjay D, Antony E, et al. Venous thromboembolism risk and prophylaxis in the acute hospital care setting (ENDORSE), a multinational cross-sectional study: Results from the Indian subset data. Indian J of Med Res. 2012;36(1):60-7. [http://www.ijmr.org.in/text. asp?2012/136/1/60/99568]

27. Bang SM, Jang MJ, Kim KHD, Yhim HY, Kim YK, Nam SH, et al. Korean Society of Thrombosis and Hemostasis. Korean guidelines for the prevention of venous thromboembolism. Journal of Korean Medical Science. 2010;25(11):1553-9.

28. The Korea Society on Thrombosis and Hemostasis. Japanese guideline for prevention of venous thromboembolism. Korean Journal of Thrombosis and Hemostasis. 2009;16(suppl 1). 